\title{
Effects of systematic and random errors on the retrieval of particle microphysical properties from multiwavelength lidar measurements using inversion with regularization
}

\author{
D. Pérez-Ramírez ${ }^{1,2,3}$, D. N. Whiteman ${ }^{1}$, I. Veselovskii ${ }^{4}$, A. Kolgotin ${ }^{4}$, M. Korenskiy ${ }^{4}$, and L. Alados-Arboledas ${ }^{2,3}$ \\ ${ }^{1}$ Mesoscale Atmospheric Processes Laboratory, NASA Goddard Space Flight Center, Greenbelt, 20771, Maryland, USA \\ ${ }^{2}$ Departamento de Física Aplicada, Universidad de Granada, Campus de Fuentenueva s/n, 18071 Granada, Spain \\ ${ }^{3}$ Centro Andaluz de Medio Ambiente (CEAMA), Universidad de Granada, Junta de Andalucía, Av. del Mediterráneo s/n, \\ 18006 Granada, Spain \\ ${ }^{4}$ Physics Instrumentation Center of General Physics Institute, Troitsk, Moscow Region, 142190, Russia
}

Correspondence to: D. Pérez-Ramírez (daniel.perezramirez@nasa.gov, dperez@ugr.es)

Received: 2 April 2013 - Published in Atmos. Meas. Tech. Discuss.: 24 May 2013

Revised: 18 September 2013 - Accepted: 30 September 2013 - Published: 7 November 2013

\begin{abstract}
In this work we study the effects of systematic and random errors on the inversion of multiwavelength (MW) lidar data using the well-known regularization technique to obtain vertically resolved aerosol microphysical properties. The software implementation used here was developed at the Physics Instrumentation Center (PIC) in Troitsk (Russia) in conjunction with the NASA/Goddard Space Flight Center. Its applicability to Raman lidar systems based on backscattering measurements at three wavelengths (355, 532 and $1064 \mathrm{~nm})$ and extinction measurements at two wavelengths (355 and $532 \mathrm{~nm}$ ) has been demonstrated widely. The systematic error sensitivity is quantified by first determining the retrieved parameters for a given set of optical input data consistent with three different sets of aerosol physical parameters. Then each optical input is perturbed by varying amounts and the inversion is repeated. Using bimodal aerosol size distributions, we find a generally linear dependence of the retrieved errors in the microphysical properties on the induced systematic errors in the optical data. For the retrievals of effective radius, number/surface/volume concentrations and fine-mode radius and volume, we find that these results are not significantly affected by the range of the constraints used in inversions. But significant sensitivity was found to the allowed range of the imaginary part of the particle refractive index. Our results also indicate that there exists an additive property for the deviations induced by the biases present in the individual optical data. This property permits the results here to be
\end{abstract}

used to predict deviations in retrieved parameters when multiple input optical data are biased simultaneously as well as to study the influence of random errors on the retrievals. The above results are applied to questions regarding lidar design, in particular for the spaceborne multiwavelength lidar under consideration for the upcoming ACE mission.

\section{Introduction}

The importance of atmospheric aerosol particles on Earth's climate and on environmental problems is widely recognized. Particularly, the Intergovernmental Panel on Climate Change 2007 (IPCC 2007) (Forster et al., 2007) stated that atmospheric aerosol particles can produce a negative radiative forcing that is comparable in magnitude, but opposite in sign, to the forcing induced by the increase in greenhouse gas concentration. However, according to the IPCC, radiative forcing by atmospheric aerosol particles has greater uncertainties (twice the estimated value of the forcing) due to the large spatial and temporal heterogeneities of atmospheric aerosols (e.g., Haywood and Boucher, 2000), the wide variety of aerosol sources (e.g., Dubovik et al., 2002), the spatial nonuniformity and intermittency of these sources (e.g., Kaufman et al., 1997), the short atmospheric lifetime of aerosols (e.g., Seinfield and Pandis, 1998), processes 
occurring in the atmosphere (Eck et al., 2010) and aerosol dynamics (e.g., Pérez-Ramírez et al., 2012).

Because of these challenges, the characterization of atmospheric aerosols is being achieved through intense observational programs using remote sensing techniques. For example, NASA has led several spaceborne missions to study aerosol properties worldwide (e.g., the MODIS instrument on the TERRA and AQUA platforms). However, satellite measurements possess lower temporal resolution than ground-based systems. For example, the AERONET global network (Holben et al., 1998) is providing large data sets of high-temporal-resolution ground-based aerosol measurements at more than 400 locations worldwide. But the aerosol retrievals by AERONET and by many satellite platforms only provide column-integrated properties. By contrast, the lidar technique offers vertical profiling of aerosols, from the first lidars in the early 1960s to the more sophisticated Raman lidars (Whiteman et al., 1992; Ansmann et al., 1992) or high-spectral-resolution lidars (HSRL) (Shipley et al., 1983; Grund and Eloranta, 1991; She, 2001; She et al., 2001). Moreover, the Nd:YAG laser has been used as the transmitter for multiwavelength Raman lidar systems (MW), which have permitted the retrieval of the profile of aerosol microphysical properties (e.g., Müller et al., 2001, 2004, 2005, 2011; Wandinger et al., 2002; Böckman et al., 2005; Noh et al., 2009; Balis et al., 2010; Alados-Arboledas et al., 2011; Tesche et al., 2011; Veselovskii et al., 2012; Papayannis et al., 2012; Wagner et al., 2013; Navas-Guzmán et al., 2013).

The first attempts to obtain aerosol microphysical properties from MW Raman lidar measurements were done at the Institute for Tropospheric Research (IFT) in Leipzig (Germany) using the regularization technique (Müller et al., 1999a, b, 2000). The first retrievals done at the IFT were based on measurements from a complex lidar system providing six backscattering $(355,400,532,710,800$ and $1064 \mathrm{~nm})$ and two extinction ( 355 and $532 \mathrm{~nm}$ ) coefficients. Following these first efforts, a software capability based on the regularization technique was developed at the Physics Instrumentation Center (PIC) in Troitsk, Russia. The retrieval code development at PIC has been further advanced and has incorporated a model of randomly oriented spheroids for retrieving dust particle properties (Veselovskii et al., 2010). Müller et al. (2001, 2004, 2005) and Veselovskii et al. (2002, 2004) demonstrated the capability of the regularization technique to retrieve aerosol microphysical properties from a lidar system that provides just five optical signals using a tripled Nd:YAG laser. The optical data provided by this system were backscatter coefficients $(\beta)$ at 355, 532 and $1064 \mathrm{~nm}$ and extinction coefficients $(\alpha)$ at 355 and $532 \mathrm{~nm}$ (hereafter this configuration is referred to as $3 \beta+2 \alpha)$. The inversion procedure makes use of averaging the solutions in the vicinity of the minimum of a penalty function (Veselovskii et al., 2002). This averaging procedure increases the reliability of the inversions even when the input optical data are affected by random errors (e.g., Veselovskii et al., 2002).
However, lidar systems are very complex and generally possess both random and systematic errors. Random errors arise naturally from the measurement process, and some preliminary random error sensitivity studies were performed by Müller et al. (1999a, b) and Veselovskii et al. (2002, 2004). But, to date, there is a lack of studies of the effects of systematic errors on the microphysical inversions. Systematic errors in lidar systems come from many different sources and need to be considered. From the hardware point of view, systematic errors can be due to, for example, nonlinearity of a photodetector or errors in calibration of the optical data or the effect of depolarization due to optical imperfections in channels that are sensitive to polarized light. From the methodological point of view, systematic errors can be caused by, for example, errors in the assumed atmospheric molecule density profile, the selection of the reference level (an "aerosol-free" region that may actually contain a small concentration of particles) or the use of an incorrect extinction-to-backscatter ratio to convert backscatter lidar measurements to extinction.

In general, we expect that systematic errors such as these can affect the retrieval. The aim of this work, therefore, is to study the sensitivity of microphysical retrievals by the regularization technique to systematic variations in the input optical data provided by the $3 \beta+2 \alpha$ lidar configuration. Particularly, we will focus on the study of bimodal size distributions widely found in nature (e.g., Dubovik et al., 2002). We will show that the results obtained can also be used to assess the sensitivity of the retrievals to random errors in a new way. The study involves simulations based on three different bimodal aerosol size distributions: one with a large predominance of fine mode, another with slight predominance of coarse mode and the last one with slight predominance of fine mode.

The procedure that we used is the following: first the optical data consistent with the three aerosol size distributions described above are generated using Mie theory. Then the optical inputs are systematically altered to provide a known amount of systematic error in each of the individual input data. The inversion code is run using both the biased and unbiased optical data, and the deviations in the retrieved aerosol parameters are quantified. The methodology and the simulation approach are presented in Sect. 2. Section 3 is devoted to the results. Finally, in Sect. 4 we present a summary and conclusions.

\section{Methodology and simulation approach}

\subsection{Inversion technique}

The optical characteristics of an ensemble of polydisperse aerosol particles are related to the particle volume distribution via Fredholm integral equations of the first kind as follows (Müller et al., 1999a; Veselovskii et al., 2002): 
$g_{j}\left(\lambda_{i}\right)=\int_{r_{\min }}^{r_{\max }} K_{j, N}\left(m, r, \lambda_{i}\right) n(r) \mathrm{d} r$,

where $j$ corresponds either to backscatter $(\beta)$ or extinction $(\alpha)$ coefficients, $g_{j}\left(\lambda_{i}\right)$ are the corresponding optical data at wavelength $\lambda_{i}, n(r)$ is the aerosol size distribution expressed as the number of particles per unit volume between $r$ and $r+\mathrm{d} r$, and $K_{j, N}\left(m, r, \lambda_{i}.\right)$ are the number kernel functions (backscatter or extinction), which are here calculated from Mie theory assuming spherical particles and depend on particle refractive index $m$, particle radius $r$ and wavelength $\lambda$. Finally, $r_{\min }$ and $r_{\max }$ correspond to the minimum and maximum radius used in the inversion. The size distribution in Eq. (1) can be written in terms of surface $\left(s(r)=4 \pi r^{2} n(r)\right)$ or volume $\left(v(r)=(4 / 3) \pi r^{3} n(r)\right)$ size distribution. The corresponding kernels are obtained by dividing $K_{j, N}\left(m, r, \lambda_{i}\right.$.) by $4 \pi r^{2}$ and (4/3) $\pi r^{3}$, respectively, and are thus given by

$K_{j, S}\left(m, r, \lambda_{i}\right)=\frac{K_{j, N}\left(m, r, \lambda_{i}\right)}{4 \pi r^{2}}$,

$K_{j, V}\left(m, r, \lambda_{i}\right)=\frac{3 K_{j, N}\left(m, r, \lambda_{i}\right)}{4 \pi r^{3}}$,

where $K_{j, S}(m, r, \lambda)$ and $K_{j, V}(m, r, \lambda)$ are the surface and volume kernel functions, respectively. Generally, the volume kernel functions are used in the retrieval procedure of aerosol microphysical properties (Heintzenberg et al., 1981; Qing et al., 1989). Thus, we perform the retrieval of volume size distribution using the volume kernel functions of Eq. (3). More details about the computation of these volume kernel functions from Mie extinction coefficients for spherical particles can be found in the references (e.g., Bohren and Huffman, 1998).

The regularization technique used here to solve Eq. (1) has been discussed extensively elsewhere (e.g., Veselovskii et al., 2002, 2004, 2005), and thus we provide here only a brief overview. The key point is to identify a group of solutions that, after averaging, can provide a realistic estimation of particle parameters. Such identification can be done by considering the discrepancy $(\rho)$ defined as the difference between input data $g(\lambda)$ and data calculated from the solution obtained. The retrieval uses an averaging procedure that consists of selecting a class of solutions in the vicinity of the minimum of discrepancy (Veselovskii et al., 2002, 2004). Such an averaging procedure stabilizes the inversion, as the final solution for size distribution and aerosol parameters is an average of a large number of individual solutions near the minimum of discrepancy (Veselovskii et al., 2002). In general, we average approximately $1 \%$ of the total number of solutions in arriving at the best estimate of the particle parameters.

The inverse problem considered here is underdetermined, so constraints on the inversion are needed. We consider a set of possible values of the particle refractive index as well as a set of possible radii within a certain size interval. In general, the retrieval result will depend on the range of parameters considered: the larger the range, the higher the uncertainty of the retrieval as determined by the spread in the solutions obtained. So the range of parameters should be chosen reasonably. In our research, the real part of the aerosol refractive index $\left(m_{\mathrm{r}}\right)$ is allowed to vary from 1.33 to 1.65 with a step size of 0.025 , while the imaginary part $\left(m_{\mathrm{i}}\right)$ varies over the range of $0-0.01$ with a step size of 0.001 . The size interval for the inversions was limited to $0.075-5 \mu \mathrm{m}$ with a step size of $0.025 \mu \mathrm{m}$. Tests revealed that reducing the step size of the different parameters in the inversion does not decrease the spread in the solution. Therefore, we take the step sizes used as adequate for the purposes of the present sensitivity study.

\subsection{Size distribution for the simulations}

For these simulations, we used bimodal aerosol size distributions given as (Veselovskii et al., 2004)

$$
\frac{\mathrm{d} n(r)}{\mathrm{d} \ln (r)}=\sum_{i=f, c} \frac{N_{t, i}}{(2 \pi)^{1 / 2} \ln \sigma_{i}} \exp \left[\frac{\left(\ln r-\ln r_{i}^{n}\right)^{2}}{2\left(\ln \sigma_{i}\right)^{2}}\right],
$$

where $N_{t, i}$ is the total particle number of the $i$ th mode, $\ln \left(\sigma_{i}\right)$ is the mode width of the $i$ th mode and $r_{i}^{n}$ is the mode radius for the number concentration distribution. The index $i=f$, $c$ corresponds to the fine mode and the coarse mode, respectively. In the retrieval procedure, the fine mode is taken to include all particles with radius between 0.075 and $0.5 \mu \mathrm{m}$, while the coarse mode includes all particles with radius between 0.5 and $5 \mu \mathrm{m}$. On the other hand, the same distribution can be written for volume concentration $v(r)$, which is usually preferred because both fine and coarse mode can be easily distinguished. Moreover, the standard deviations of $n(r)$ and $v(r)$ are the same when using the relationships between radius and concentrations for each mode given by (Horvath et al., 1990)

$r_{i}^{v}=r_{i}^{n} \exp \left[3(\ln \sigma)^{2}\right]$,

$V_{t i}=N_{t i} \frac{4}{3} \pi\left(r_{i}^{n}\right)^{3} \exp \left[\frac{9}{2}(\ln \sigma)^{2}\right]$.

We consider three types of aerosol size distributions for the simulations, which we call type I, type II and type III. These size distributions are used to approximate real aerosol types found in the atmosphere. All types use $r_{f}^{v}=0.14 \mu \mathrm{m}$, $\ln \sigma_{f}=0.4, r_{c}^{v}=1.5 \mu \mathrm{m}$ and $\ln \sigma_{c}=0.6$. These mode radii and widths are representative of those provided by Dubovik et al. (2002) in the AERONET climatology database and are thus considered to represent a large fraction of naturally occurring aerosols. The differences between type I, II and III are the ratio of fine and coarse mode $\left(V_{\mathrm{tf}} / V_{\mathrm{tc}}\right)$. Type I yields $V_{\mathrm{tf}} / V_{\mathrm{tc}}=2$ and represents a distribution with a predominance of fine mode. This type can be considered to represent industrial and biomass burning aerosols (e.g., Eck et al., 
2003; Müller et al., 2004; Schafer et al., 2008). Type II yields $V_{\mathrm{tf}} / V_{\mathrm{tc}}=0.2$ and corresponds to a slight predominance of the coarse mode over the fine mode. This type is consistent with a mixture of dust/marine aerosol and those of pollution or biomass burning (e.g., Smirnov et al., 2002, 2003; Eck et al., 2005, 2010). Finally, type III yields $V_{\mathrm{tf}} / V_{\mathrm{tc}}=1$ and corresponds to a slight predominance of fine mode over the coarse mode (e.g., Xia et al., 2007; Ogunjobi et al., 2008; Yang and Wenig, 2009; Eck et al., 2009). This type is representative of predominance of pollution or biomass burning but with considerable influence of dust particles. Figure 1 illustrates the three size distributions used. For convenience, the size distributions of Fig. 1 are normalized. Finally, if we were to include a strong predominance of coarse mode (e.g., marine or dust aerosol) in $3 \beta+2 \alpha$ lidar measurements, then the effects of polarization and nonsphericity should be taken into account, and previous work indicates that the use of kernel functions for nonspherical particles can improve the retrievals (Veselovskii et al., 2010). Here, however, our purpose is to calculate sensitivities due to random and systematic uncertainties, so we consider only spherical (Mie) kernels and thus exclude a distribution with a strong predominance of the coarse mode.

The simulation consists in generating the three backscattering and two extinction coefficients for the $3 \beta+2 \alpha$ lidar configuration using Mie theory for the three aerosol size distributions: type I, type II and type III. These optical data are generated for six different configurations of aerosol refractive indices $\left(m_{\mathrm{r}}\right.$ values of $1.35,1.45$ and 1.55 and $m_{\mathrm{i}}$ either 0.005 or 0.01). From previous studies (Müller et al., 1999b; Veselovskii et al., 2002), error in $m_{\mathrm{r}}$ was initially established as \pm 0.05 , while error in $m_{\mathrm{i}}$ was approximately $50 \%$. Moreover, the AERONET network provides refractive indices with very similar errors (Dubovik et al., 2000). Thus, the range of refractive indexes proposed for the size distribution is enough to cover most of the values obtained by AERONET (Dubovik et al., 2002).

The regularization inversion is then performed on these data and we obtain the retrieved microphysical parameters $M_{\text {ret }}$. The next step consists of applying a systematic bias, denoted as $\Delta \varepsilon$, to one optical datum at a time. The bias varies from -20 to $+20 \%$ in eight intervals. For each of these induced biases, the inversion is performed and a new size distribution and set of microphysical parameters, $M_{\text {bias }}$, are then obtained. The comparisons to be performed are expressed as the percentage difference $100 \cdot\left(M_{\text {bias }}-M_{\text {ret }}\right) / M_{\text {ret }}$. This procedure is applied to each of the five optical data used in the $3 \beta+2 \alpha$ lidar configuration.

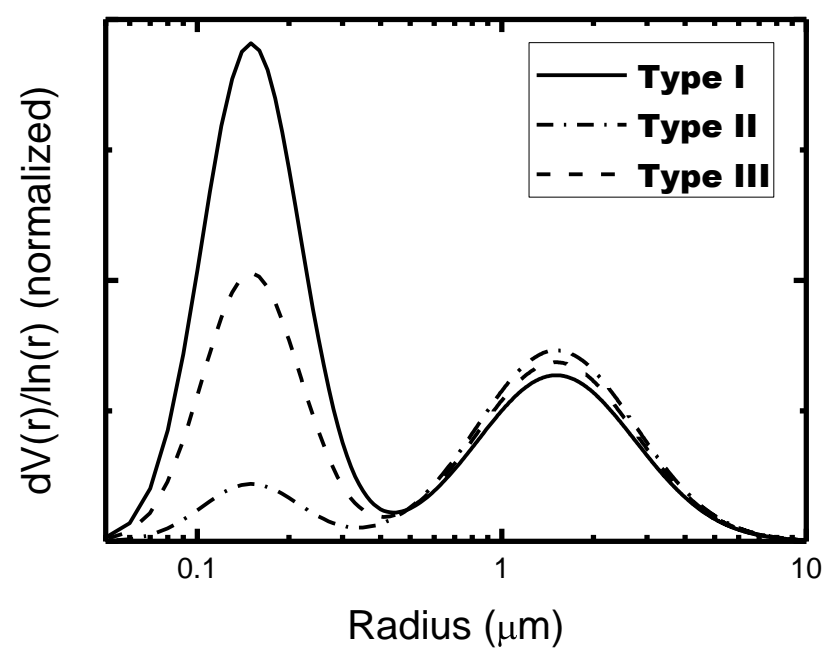

Fig. 1. Normalized size distributions used for computing the simulated optical data. The ratio between the volume of fine and coarse mode, $V_{\mathrm{tc}} / V_{\mathrm{tc}}$, is 2 for type I, 0.2 for type II and 1 for type III.

\section{Results}

\subsection{Uncertainties in the retrieval of particle refractive index}

The $3 \beta+2 \alpha$ lidar configuration permits the retrieval of particle refractive index, both real $\left(m_{\mathrm{r}}\right)$ and imaginary $\left(m_{\mathrm{i}}\right)$ parts (e.g., Veselovskii et al., 2002), by the use of the regularization scheme. But the inverse problem of Eq. (1) is underdetermined and, as already stated, constraints are needed to permit solutions to be obtained. Particularly, the selection of the range of refractive indices permitted in the retrieval is important. As commented, we limited the range of $m_{\mathrm{r}}$ to between 1.33 and 1.65 and $m_{\mathrm{i}}$ from 0.0 up to 0.01 . These ranges cover most types of aerosol particles present in the atmosphere, except for strongly absorbing particles such as black carbon. Moreover, given that the longest wavelength measurement used here is $1064 \mathrm{~nm}$, the technique has reduced sensitivity to the coarse mode of the aerosol distribution. Thus, to stabilize the retrievals, the maximum radius of the retrieval interval was set to $5 \mu \mathrm{m}$. Additionally, the kernel functions for radius below 0.075 are very near to zero, and thus the minimum radius allowed was set to $0.075 \mu \mathrm{m}$. The behavior of the kernel functions versus wavelength can be consulted, for example, in Chapter 11 of Bohren and Huffman (1998).

In the analysis that follows, we do not present results on the refractive index sensitivity analysis. The reason for this is that we found that the retrieval of refractive index is very sensitive to the range of permitted values for the imaginary part of the refractive index. Changing the range of permitted values of the imaginary part can change the retrieved refractive index significantly while not significantly affecting the values of the other retrieved quantities. For example, computations allowing $m_{\mathrm{i}}$ to range up to 0.1 provide retrieved 
values of $m_{\mathrm{i}}$ of approximately 0.03 when the values of $m_{\mathrm{i}}$ of the input size distributions where 0.01 or 0.005 . Therefore, keeping in mind that the retrieval is underdetermined, we conclude that we can provide reasonable estimates of the refractive index only with reasonable constraints for $m_{\mathrm{i}}$. All these results just magnify the point that refractive index retrievals are difficult with the MW lidar technique and that some a priori knowledge of the aerosol absorption is helpful to constrain the inversion. A more detailed discussion about the limitations of the averaging procedure used here to retrieve accurate values of particle refractive index is in Veselovskii et al. (2013).

\subsection{Effects on the retrievals of systematic errors in the optical data}

For the scheme described previously, Fig. 2 presents the sensitivity analysis for the retrieval of effective radius $\left(r_{\text {eff }}\right)$. Every point corresponds to the mean value of the six different combinations of aerosol refractive indices used in generating the set of optical data. The error bars shown are the standard deviations of these mean values. Generally linear patterns are observed for the deviation in the retrieved value of $r_{\text {eff }}$ for differing biases in the input optical data for all of types I, II and III aerosols. As the linear patterns pass through the origin, least-squares fits of the form $Y=a X$ were performed for the points shown in the plot. Given the definition of $\Delta r_{\text {eff }}=r_{\text {eff, bias }}-r_{\text {eff, ret }}$, positive slopes indicate higher values of $r_{\text {eff }}$ when the optical data are affected by positive biases than when they are not affected by biases, while for negative slopes just the opposite occurs. Moreover, Fig. 2 reveals the same general patterns for all of types I, II and III for each optical channel, with only small changes in the absolute values of the slopes of the linear fits. It is quite apparent that the retrievals are more sensitive to biases in the extinction coefficients. The lowest sensitivities are to biases in $\beta(355 \mathrm{~nm})$ and $\beta(532 \mathrm{~nm})$, while for biases in $\beta(1064 \mathrm{~nm})$, the sensitivity of the retrievals is in between those obtained for extinction and backscattering coefficients at 355 and $532 \mathrm{~nm}$. Figure 2 also reveals that the linear patterns for different optical channels have different signs of the slopes. Considering the parameters to which the retrievals are most sensitive, the linear fit of $\alpha(355 \mathrm{~nm})$ gives negative values of slope $(a=-1.68 \pm 0.12$ for type I, $a=-1.74 \pm 0.03$ for type II and $a=-1.84 \pm 0.04$ for type III), while for $\alpha(532 \mathrm{~nm})$ the slopes are positive ( $a=1.51 \pm 0.04$ for type I, $a=1.82 \pm 0.09$ for type II and $a=1.71 \pm 0.10$ for type III).

The Ångström law, either for the extinction $\alpha(\lambda)=k \lambda-\eta \alpha$ or for the backscattering $\beta(\lambda)=k \lambda^{-\eta \beta}$, can be used to help understand the sign of the slopes of Fig. 2. For the wavelengths used here, the Ångström exponents $\eta_{\alpha}$ and $\eta_{\beta}$ characterize the spectral features of aerosol particles and are related to the size of the particles: large values of $\eta_{\alpha}$ and $\eta_{\beta}$ are mainly associated with predominance of fine-mode particles, while low values are associated with a predominance of
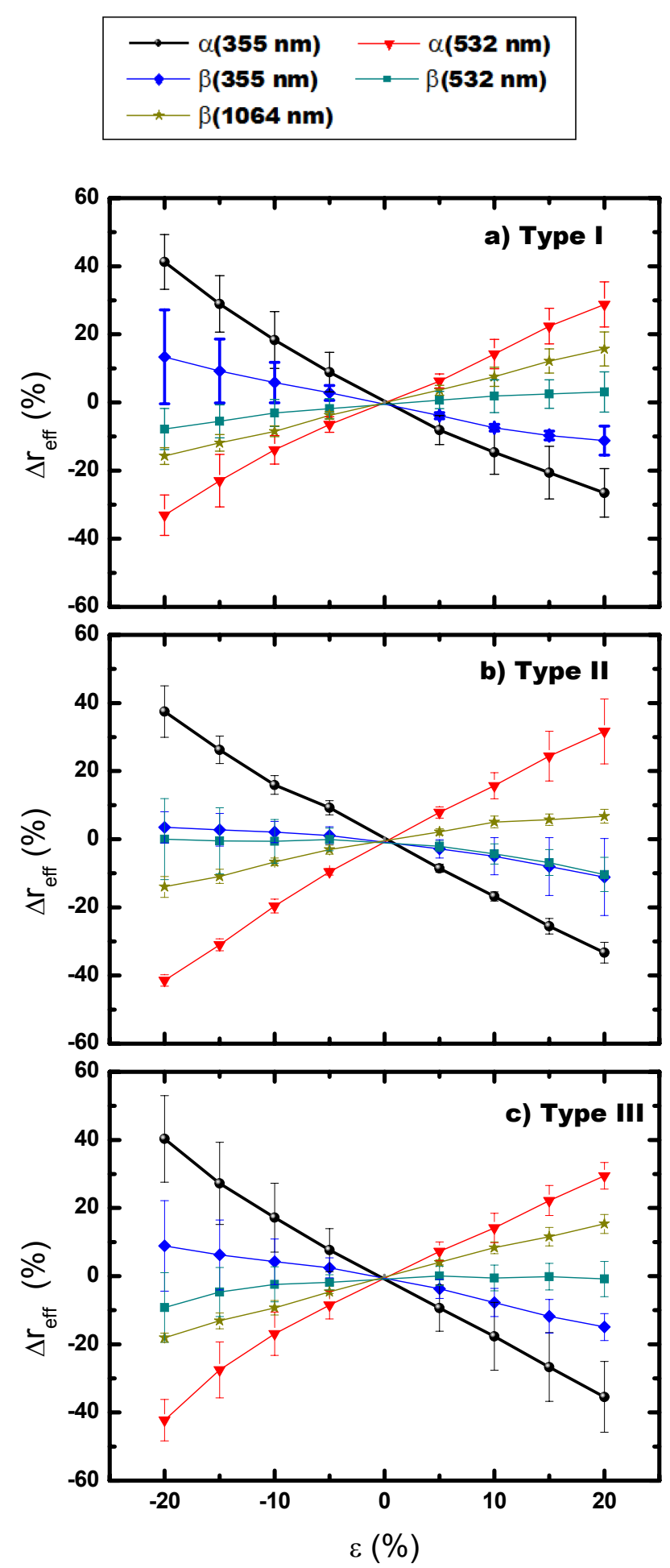

Fig. 2. Percentage deviation of the effective radius as a function of systematic bias in the optical data $(\varepsilon)$. (a) Type I, (b) type II and (c) type III. 
coarse mode (e.g., Dubovik et al., 2002). Moreover, many works (e.g., Alados-Arboledas et al., 2003; O'Neill et al., 2005; Veselovskii et al., 2009) have found an inverse relationship between the Ångström exponent for extinction and the effective radius: large values of the Ångström exponent are associated with low values of $r_{\text {eff }}$, while just the opposite occurs for low values of the Ångström exponent. Considering this and given that $\alpha(355 \mathrm{~nm})$ is generally larger than $\alpha(532 \mathrm{~nm})$, a positive bias in $\alpha(355 \mathrm{~nm})$ increases the spectral difference with $\alpha(532 \mathrm{~nm})$ and would increase the value of the Angström exponent and thus would result in a decrease in the retrieved particle radius. This agrees with the negative slopes of $\alpha(355 \mathrm{~nm})$ observed in Fig. 2. On the other hand, a positive bias in $\alpha(532 \mathrm{~nm})$ reduces the spectral difference with $\alpha(355 \mathrm{~nm})$ and thus serves to decrease $\eta_{\alpha}$. Thus, we would expect an increase in the retrieved particle radius, which agrees with the positive slopes observed for $\alpha(532 \mathrm{~nm})$ in Fig. 2. The slopes of $\beta(355 \mathrm{~nm})$ and $\beta(532 \mathrm{~nm})$ possess mostly the same sign as the corresponding extinction coefficient at each wavelength, and similar logic concerning the relationship of the Angström exponent and the particle size given for $\alpha(355 \mathrm{~nm})$ and $\alpha(532 \mathrm{~nm})$ can be used to explain this behavior as well. Finally, for $\beta(1064 \mathrm{~nm})$ we observe positive slopes $(a=0.791 \pm 0.008$ for type I, $a=0.54 \pm 0.07$ for type II and $a=0.84 \pm 0.02$ for type III). Positive biases of $\beta(1064 \mathrm{~nm})$ decrease the spectral difference between $\beta(355 \mathrm{~nm})$ and $\beta(532 \mathrm{~nm})$, indicating a decrease of the Ångström exponent, and thus we would expect an increase in the retrieved particle size, which agrees with the presence of positive slopes in the plot.

Figure 3 presents the sensitivity analysis for the retrieval of number concentration $(N)$. From Fig. 3 we again generally observe linear patterns of the deviation in retrieved value of $N$ for differing biases in the input optical data. Linear fits through the origin in the forms $Y=a X$ were also performed here. Interestingly, the slopes of the linear fits of the extinction coefficients present opposite signs to those determined for the retrieval of $r_{\text {eff }}$, with positive values for $\alpha(355 \mathrm{~nm})(a=3.09 \pm 0.12$ for type I, $a=4.83 \pm 0.22$ for type II $a=3.04 \pm 0.13$ for type III) and negative values for $\alpha(532 \mathrm{~nm})(a=-2.78 \pm 0.17$ for type I, $a=-4.09 \pm 0.23$ for type II and $a=-2.61 \pm 0.12$ for type III). Therefore, we see in the retrieved results, for example, that in order to compensate for a radius enhancement due to biased input data, the retrieval tends to decrease number density.

For the sensitivities of $r_{\text {eff }}$ and $N$ shown in Figs. 2 and 3, the absolute values of the slopes at $\alpha(355 \mathrm{~nm})$ and $\alpha(532 \mathrm{~nm})$ are larger than 1 , which indicates that the percentage deviations in the retrieved $r_{\text {eff }}$ and $N$ using biased data are larger than the percentage bias imposed on the input optical data. Thus, the accuracy of $r_{\text {eff }}$ retrievals using $3 \beta+2 \alpha$ lidar is strongly dependent on the accuracy associated with the extinction coefficients. Other slopes with absolute values less than 1 , as for example those obtained for $r_{\text {eff }}$ as a function of biases in $\beta(1064 \mathrm{~nm})$, indicate that while the retrieval is still
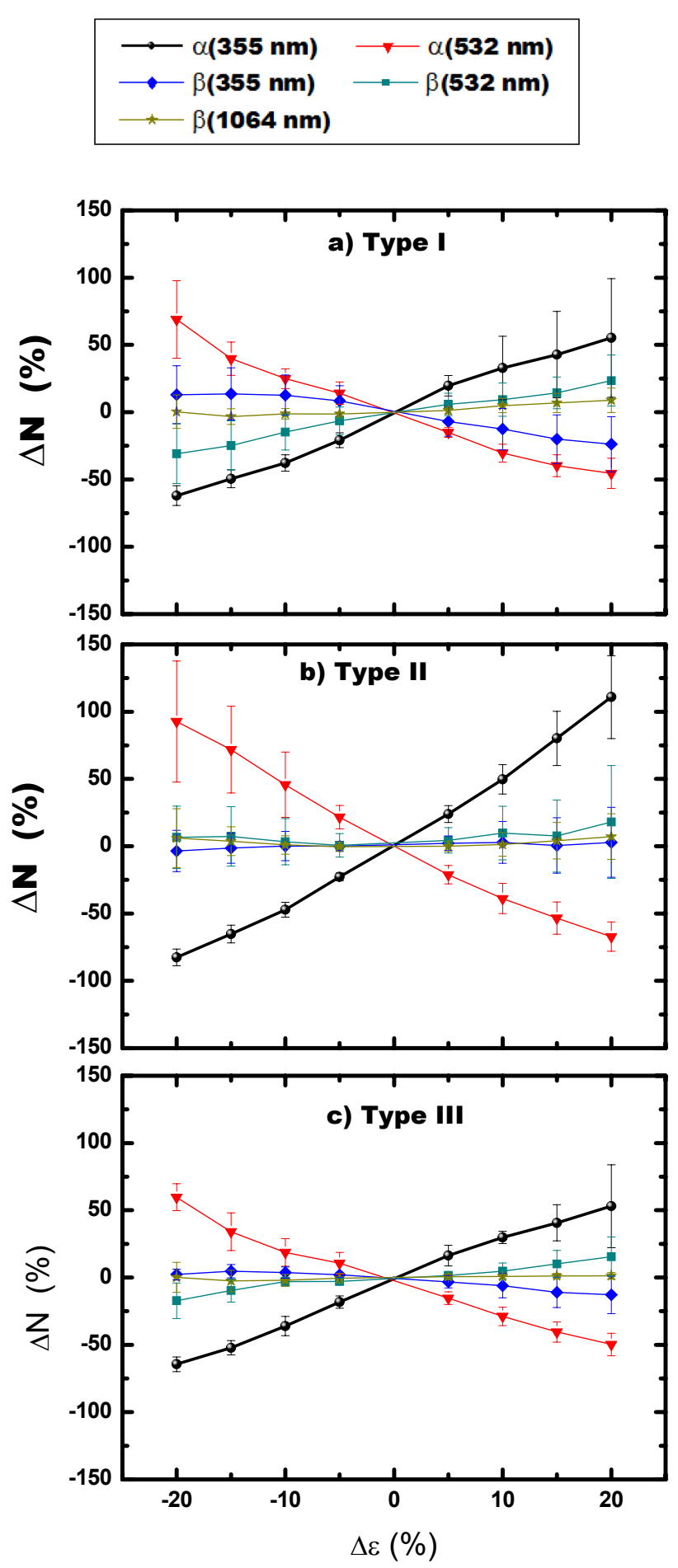

Fig. 3. Percentage deviation of the number concentration as a function of systematic bias in the optical data $(\varepsilon)$. (a) Type I, (b) type II and (c) type III. 
Table 1. Percentage deviations in the aerosol microphysical properties as a function of systematic errors in the optical data $\varepsilon$. Particularly, the slopes $a$ of the linear fits $Y=a X$ are presented, where $X$ is the systematic bias in the optical data and $Y$ is the corresponding deviation in the microphysical properties. All these fits presented linear determination coefficient $R^{2}>0.90$. For the cases when there is a difference in slope between positive and negative biases in the input data, the slopes relating to the positive biases are indicated by ( $p$ ), while those associated with negative biases are indicated by $(n)$.

\begin{tabular}{|c|c|c|c|c|c|c|c|}
\hline & & $\frac{\Delta r_{\text {eff }}(\%)}{\Delta \varepsilon(\%)}$ & $\frac{\Delta N(\%)}{\Delta \varepsilon(\%)}$ & $\frac{\Delta S(\%)}{\Delta \varepsilon(\%)}$ & $\frac{\Delta V(\%)}{\Delta \varepsilon(\%)}$ & $\frac{\Delta r_{\text {fine }}(\%)}{\Delta \varepsilon(\%)}$ & $\frac{\Delta V_{\text {fine }}(\%)}{\Delta \varepsilon(\%)}$ \\
\hline \multirow{3}{*}{ 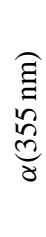 } & Type I & $-1.68 \pm 0.12$ & $3.09 \pm 0.12$ & $2.08 \pm 0.05$ & $\begin{array}{l}0.26(p) / \\
0.77(n), \pm 0.07\end{array}$ & $-0.99 \pm 0.11$ & $1.59 \pm 0.05$ \\
\hline & Type II & $-1.74 \pm 0.03$ & $4.83 \pm 0.22$ & $1.77 \pm 0.04$ & $\begin{array}{l}-0.37(p) / \\
0.35(n) \pm 0.05\end{array}$ & $-1.27 \pm 0.17$ & $1.66 \pm 0.17$ \\
\hline & Type III & $-1.84 \pm 0.04$ & $3.04 \pm 0.13$ & $1.95 \pm 0.05$ & $\begin{array}{l}-0.47(p) / \\
0.77(n) \pm 0.04\end{array}$ & $\begin{array}{l}-0.64(p) / \\
-1.51(n) \pm 0.07\end{array}$ & $1.56 \pm 0.06$ \\
\hline \multirow{3}{*}{ 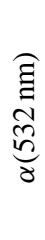 } & Type I & $1.51 \pm 0.04$ & $-2.78 \pm 0.17$ & $-1.07 \pm 0.08$ & $0.44 \pm 0.12$ & $1.17 \pm 0.04$ & $-0.28 \pm 0.05$ \\
\hline & Type II & $1.82 \pm 0.09$ & $-4.09 \pm 0.23$ & $-0.69 \pm 0.03$ & $1.18 \pm 0.17$ & $1.28 \pm 0.07$ & $-0.44 \pm 0.04$ \\
\hline & Type III & $1.71 \pm 0.10$ & $-2.61 \pm 0.12$ & $-0.92 \pm 0.07$ & $\begin{array}{l}1.46 \pm 0.08(p) / \\
0.77(n) \pm 0.02\end{array}$ & $\begin{array}{l}0.98(p) \pm 0.01 / \\
1.46(n) \pm 0.01\end{array}$ & $-0.20 \pm 0.04$ \\
\hline \multirow{3}{*}{ 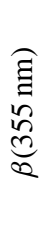 } & Type I & $-0.63 \pm 0.02$ & $\begin{array}{l}-1.25 \pm 0.04(p) / \\
-0.85 \pm 0.15(n)\end{array}$ & $-0.73 \pm 0.04$ & $-1.39 \pm 0.04$ & $\begin{array}{l}-0.01(p) / \\
-0.06(n) \pm 0.01\end{array}$ & $-0.62 \pm 0.03$ \\
\hline & Type II & $\begin{array}{l}-0.54(p) / \\
-0.18(n) \pm 0.01\end{array}$ & $\begin{array}{l}0.19(p) / \\
0.12(n) \pm 0.04\end{array}$ & $\begin{array}{l}-0.22(p) / \\
-0.04(n) \pm 0.02\end{array}$ & $-0.48 \pm 0.10$ & $\begin{array}{l}0.33(p) / \\
0.06(n) \pm 0.03\end{array}$ & $\begin{array}{l}0.26(p) / \\
-0.01(n) \pm 0.01\end{array}$ \\
\hline & Type III & $\begin{array}{l}-0.76(p) / \\
-0.43(n) \pm 0.01\end{array}$ & $-0.44 \pm 0.08$ & $-0.47 \pm 0.06$ & $-1.04 \pm 0.08$ & $0.10 \pm 0.01$ & $\begin{array}{l}-0.39(p) / \\
-0.19(n) \pm 0.01\end{array}$ \\
\hline \multirow{3}{*}{ 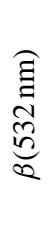 } & Type I & $0.27 \pm 0.04$ & $1.3 \pm 0.09$ & $0.50 \pm 0.03$ & $0.77 \pm 0.05$ & $\begin{array}{l}-0.05(p) / \\
-0.22(n) \pm 0.03\end{array}$ & $0.22 \pm 0.02$ \\
\hline & Type II & $\begin{array}{l}-0.48(p) / \\
0.02(n) \pm 0.02\end{array}$ & $\begin{array}{l}0.79 \pm 0.11(p) / \\
-0.37 \pm 0.05(n)\end{array}$ & $0.05 \pm 0.02$ & $\begin{array}{l}-0.38(p) / \\
0.03(n) \pm 0.03\end{array}$ & $-0.11 \pm 0.02$ & $\begin{array}{l}-0.11(p) / \\
-0.34(n) \pm 0.01\end{array}$ \\
\hline & Type III & $\begin{array}{l}-0.03(p) / \\
0.38(n) \pm 0.05\end{array}$ & $0.70 \pm 0.06$ & $0.30 \pm 0.03$ & $0.48 \pm 0.07$ & $-0.16 \pm 0.01$ & $0.02 \pm 0.02$ \\
\hline \multirow{3}{*}{ 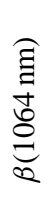 } & Type I & $0.79 \pm 0.01$ & $0.37 \pm 0.05$ & $0.17 \pm 0.02$ & $0.92 \pm 0.04$ & $-0.17 \pm 0.01$ & $-0.04 \pm 0.01$ \\
\hline & Type II & $0.54 \pm 0.07$ & $\begin{array}{l}0.29(p) / \\
-0.25(n) \pm 0.05\end{array}$ & $0.04 \pm 0.02$ & $0.60 \pm 0.05$ & $-0.28 \pm 0.02$ & $\begin{array}{l}-0.15(p) / \\
-0.34(n) \pm 0.02\end{array}$ \\
\hline & Type III & $0.84 \pm 0.02$ & $0.07 \pm 0.03$ & $0.08 \pm 0.02$ & $0.92 \pm 0.03$ & $-0.26 \pm 0.01$ & $-0.19 \pm 0.01$ \\
\hline
\end{tabular}

quite sensitive to biases in $\beta(1064 \mathrm{~nm})$, the deviations in the retrieved parameters is less than the magnitude of the biases. Finally, the slopes of $r_{\text {eff }}$ as a function of biases in the input data for $\beta(355 \mathrm{~nm})$ and $\beta(532 \mathrm{~nm})$ are quite small, indicating that biases in these optical parameters have relatively small effects on the retrieval of $r_{\text {eff. }}$. However, for the retrieval of number concentration, the effects of biases in the backscattering optical data are not negligible, with absolute values of the slopes of the linear fits between 1.3 and 0.3.

As with the effective radius and number concentration, we have performed the sensitivity analysis for the other microphysical parameters obtained from the inversion of $3 \beta+2 \alpha$ lidar data. For these studies, we have also observed generally linear patterns when considering the differences in the retrieved microphysical parameters as a function of the bias in the input optical data. Again, the linear patterns pass through the origin, and we therefore assumed least-squares fits of the form $Y=a X$. The results of the linear fits for all the parameters are summarized in Table 1, including also the slopes obtained for $r_{\text {eff }}$ and $N$ in Figs. 2 and 3, respectively.

We note that for some parameters the linear fit possesses different slopes for positive and negative biases $\Delta \varepsilon$. For example, in the case of $r_{\text {eff }}$ for type II, $\beta(532 \mathrm{~nm})$ has a slope of $-0.48 \pm 0.02$ for positive biases and $0.02 \pm 0.02$ for negative biases. This is taken into account in Table 1, where, if there is a difference in slope between positive and negative biases in the input data, then the slopes relating to the positive biases are indicated by $(p)$, while those associated with negative biases are indicated by $(n)$. We take this difference in slope to be a reflection of the reduced sensitivity to the coarse mode 
of the distribution. From Table 1 we observe that the number concentration is by far the most sensitive parameter to bias in the optical data, particularly to those biases in $\alpha(355 \mathrm{~nm})$ and $\alpha(532 \mathrm{~nm})$. Moreover, the sensitivities to biases at $\beta(355 \mathrm{~nm})$ are generally larger for type I than for type II (absolute values of slopes are larger), with type III being in the middle. This finding can be explained by the fact that, for the same total volume, small particles (which predominate in type I) generally provide larger backscattering of light at the shorter wavelengths (phase function at $180^{\circ}$ is larger) (e.g., Mischenko et al., 2000; Liou, 2002; Kokhanovsky 2004).

From Table 1 the slopes calculated from the linear fits of surface concentration $(S)$ as a function of biases in the optical data present the same patterns (sign of slopes) between types I, II and III. The difference in the absolute values of slopes between the three types are then associated with the differences in the size distribution and with the changes in the kernel functions. The largest sensitivities of $S$ are found for biases at $\alpha(355 \mathrm{~nm})$ (absolute values of slopes $\sim 2.0$ ). Sensitivities to biases at $\alpha(532 \mathrm{~nm})$ (absolute values of slopes between 1.07 and 0.69 ) are also important for type I, II and III, while the sensitivity associated with $\beta(355 \mathrm{~nm})$ is only remarkable for type I (slope of $-0.73 \pm 0.04$ ). Sensitivities to biases at $\beta(532 \mathrm{~nm})$ and $\beta(1064 \mathrm{~nm})$ are quite low (absolute values of slopes below 0.5 ).

Referring back to Table 1, we observe that the volume concentration $(V)$ is the retrieved integrated parameter least affected by bias in the input optical data, as indicated by the fact that most of the slopes have absolute values below 1.0. However, we found differences among these three different aerosol types. For type I aerosols, the retrieval of volume concentration is most sensitive to biases in $\beta(355 \mathrm{~nm})$ (slope of -1.39 ), while for type II aerosols, retrievals are most sensitive to deviations in $\alpha(532 \mathrm{~nm})$ (slope of 1.18). For type III aerosols the sensitivities to bias in the optical data are important both at $\beta(355 \mathrm{~nm})$ (slope of -1.04$)$ and at $\alpha(532 \mathrm{~nm}$ ) (slope up to 1.46$)$. These differences among the aerosol types I, II and III demonstrate the different sensitivities of volume concentration retrievals when the aerosol size distribution possesses different weights of fine and coarse mode.

As the regularization scheme used here computes the size distribution using the range of permitted radii of $0.075-5 \mu \mathrm{m}$, the fine-mode part of the distribution (but not the coarse mode) is completely covered by this inversion window, and thus we study fine-mode volume radius $\left(r_{\text {fine }}\right)$ and fine-mode volume concentration $\left(V_{\text {fine }}\right)$. Table 1 also shows the sensitivities of these two parameters to biases in the input optical data. From the slopes of the linear fits reported for $r_{\text {fine }}$, biases in $\alpha(355 \mathrm{~nm})$ and $\alpha(532 \mathrm{~nm})$ produce significant deviations in the retrieval, with absolute values of the slopes approximately between 1.0 and 1.5 , while the deviations in the retrievals created by biases in other optical parameters are almost negligible. This result would imply that accurate retrievals of $r_{\text {fine }}$ can tolerate rather large errors in the backscatter data but not in the extinction data. The sign of the slopes of $r_{\text {fine }}$ as a function of $\alpha(355 \mathrm{~nm})$ and $\alpha(532 \mathrm{~nm})$ can be explained by the same reasoning given before for the effective radius: as extinction at $355 \mathrm{~nm}$ increases, it makes the retrieved particle radius decrease. But as $\alpha(532 \mathrm{~nm})$ increases the retrieved particle radius increases. On the other hand, for the $V_{\text {fine }}$, the largest sensitivities in the retrieval are found to systematic biases at $\alpha(355 \mathrm{~nm})$, with slopes of $1.59 \pm 0.05$, $1.66 \pm 0.17$ and $1.56 \pm 0.06$ for types I, II and III, respectively. For the other optical parameters, absolute values of the slopes are below 0.5 (except $\beta(1064 \mathrm{~nm}$ ) for type I with slope of $0.62 \pm 0.03$ ). These dependencies of the sensitivities of $r_{\text {fine }}$ and $V_{\text {fine }}$ to biased input data are associated with the different dependencies of the kernel functions on wavelength and particle radius (e.g., Chapter 11 of Bohren and Huffman, 1998).

At this point we would like to mention that our simulations (graphs not shown for brevity) showed some departures from the linearity shown in Figs. 2 and 3 and Table 1 for systematic errors larger than approximately $\pm 30 \%$, mainly when the absolute values of the slopes are larger than 1 . We take this to be an indication that biases of approximately $\pm 30 \%$ and larger can cause the regularization routine to choose a different solution space than the original retrieval based on data with no errors. On the other hand, up to errors of $\pm 20 \%$, we find that the same minimum in the solution space is generally found by the routine, so the linear behavior seen in Figs. 2 and 3 is taken to be a characteristic of a stable system that is displaced from its minimum point. Therefore, we selected a threshold value of $\pm 20 \%$ where these results are applicable and stress that larger errors in the input data can cause significant and unpredictable deviations in the retrieved results.

Finally, we remark that the values given in Table 1 are averaged for the particular size distributions used here. More simulations performed (graphs not shown for brevity) changing the fine-mode radius between 0.08 and $0.20 \mu \mathrm{m}$, for aerosol types I, II and III, revealed the same average linear patterns as those shown in Figs. 2 and 3 and in Table 1. The only differences observed were in the absolute values of the slopes with differences within $10 \%$. On the other hand, no important departures from the linearity observed in Table 1 were found by changing the widths of the fine mode. Changes in the coarse mode were not tested because of the difficulty to assess retrievals of the coarse mode with the methodology used here.

\subsubsection{Effects of the constraints used in the retrievals on the sensitivity test results}

The sensitivity tests applied to the different sets of data have shown linear dependencies. The data presented in Table 1 of the linear fits allow for the computation of the deviations induced in retrieved quantities due to biases in the input data in an easy and straightforward way. But the generality of the results for different constraints in the inversion code needs 

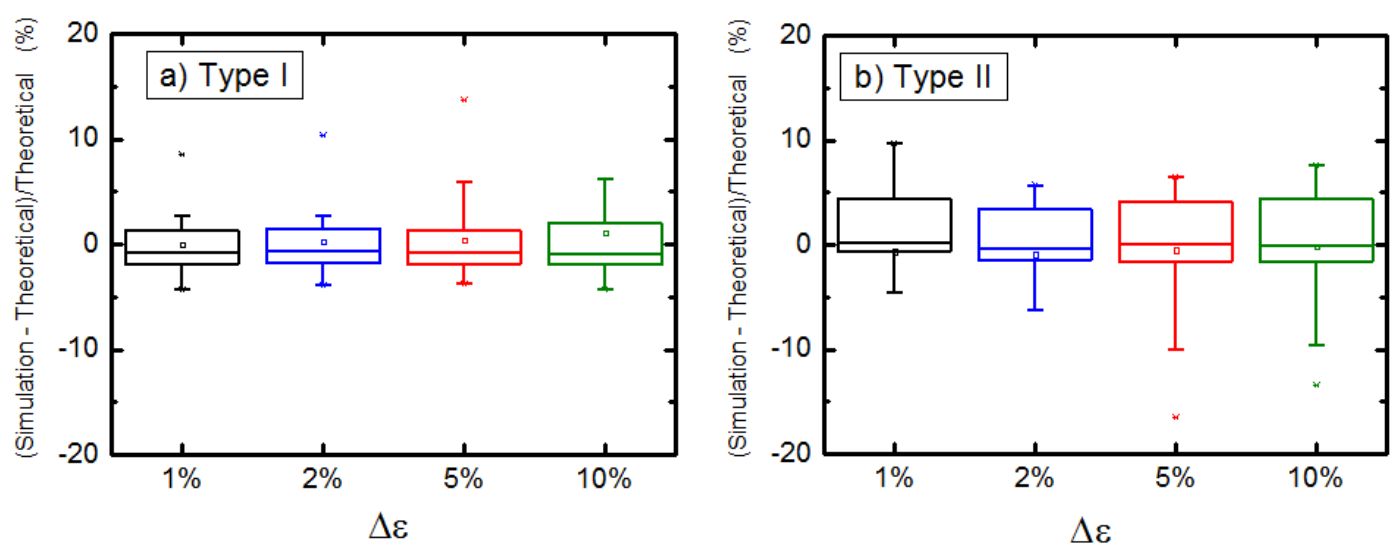

Fig. 4. For the effective radius, box-and-whisker diagrams of the differences between the theoretical deviations computed with the slopes of Table 1 and the simulated deviations. At least two optical channels have been simultaneously perturbed by biases of the same magnitude although different combinations of over/underestimations are allowed. In these box diagrams the mean is represented by an open square. The line segment in the box is the median. The top limit represents the 75th percentile (P75) and the bottom limit the 25th percentile (P25). The box bars are related to the 1st (P1) and 99th (P99) percentiles, and the crosses represent the maximum and minimum values, respectively. We used biases in the optical data of 1 (black diagrams), 2 (blue diagrams), 5 (red diagrams) and $10 \%$ (green diagrams).

to be examined. For example, the results presented in Table 1 have been based on a maximum radius in the inversion $\left(r_{\max }\right)$ of $5 \mu \mathrm{m}$. Although for the aerosol size distributions studied here this $r_{\max }$ makes the computation more efficient, the selection of $r_{\text {max }}$ depends on the user and becomes a constraint in the inversion procedure. Thus, we performed more simulations with $r_{\max }$ increased to a value of $10 \mu \mathrm{m}$ to study the influence of this change in constraint on the retrieved results. Another constraint in the inversion that must be checked is the maximum value allowed for $m_{\mathrm{i}}$. We repeated the simulations allowing $m_{\mathrm{i}}$ to range up to 0.1 (consistent with a very absorbing aerosol like black carbon). The results of these studies were compared with a baseline retrieval obtained with $r_{\max }=5 \mu \mathrm{m}$ and with maximum value of $m_{\mathrm{i}}$ of 0.01 . To compute the baseline microphysical parameters, no induced systematic errors were included. We also computed the retrievals using the new constraints and introducing systematic errors in the optical data as done before.

The new simulations performed after changing the constraints for $r_{\max }$ and maximum $m_{\mathrm{i}}$ also reveal linear patterns (graphs not shown for brevity). However, these linear patterns do not pass through the origin, implying that there are generally shifts in the retrieved values of the various parameters due to these changes in constraints. The analysis reveals, though, that the signs of the slopes of the linear fits remain the same and that very similar deviations in the retrieved quantities are computed using the linear fits performed. Therefore, while the selection of exact value of the constraints for $r_{\max }$ and $m_{\mathrm{i}}$ can change the mean values of the different parameters, the sensitivity to induced biases in the input optical data is generally unchanged by these changes in constraints.

\subsubsection{Additive properties of the effects of systematic errors in the optical data}

Thus far, the sensitivity tests that have been performed were based on perturbing a single optical input at a time. But in a real instrument, it is quite possible that two or more input data might be influenced by biases simultaneously. Therefore, we need to study the effects of the presence of multiple simultaneous biases in the input data since the existence of such biases would presumably not be known in a real application. In other words, we wish to determine if the preceding results based on perturbing a single optical input at a time can be generalized to predict the effects of multiple input data being simultaneously biased. In particular, we will now test if, when multiple inputs are simultaneously biased, the results from Table 1 can be used to calculate deviations that can simply be added to determine the total bias. In other words, we now will test whether the results in Table 1 can be considered additive.

To test the additive properties of the results shown in Table 1, we performed a set of simulations where two or more optical channels were perturbed simultaneously by biases of the same magnitude but allowing for different signs (over/underestimation). For example, let us assume that we have systematic errors of absolute magnitude of $5 \%$. Then different combinations of $\pm 5 \%$ are allowed, as for example at $\alpha(355 \mathrm{~nm})$ and $\alpha(532 \mathrm{~nm})$, at $\alpha(355 \mathrm{~nm})$ and $\beta(532 \mathrm{~nm})$ or at $\beta(355 \mathrm{~nm}), \beta(532 \mathrm{~nm})$ and $\beta(1064 \mathrm{~nm})$. This procedure was repeated for different sets of biases of magnitude up to $10 \%$. The deviations noted as "baseline" were computed using the slopes of Table 1 and assuming that the deviations are additive. We also performed the regularization retrieval with the new set of data affected by two or more simultaneous biases, called "simulated deviations". Later we computed 
the differences in the microphysical properties based on the slopes given in Table 1 and those actually retrieved running the code with the new biased optical data and then characterized the differences. Using this procedure, we generated for each absolute value of bias a statistical data set that includes many different configurations of the different optical channels. Those data sets are analyzed using Bow-Whisker diagrams as shown in Fig. 4 for the effective radius.

In these box diagrams the mean is represented by an open square. The line segment in the box is the median. The top limit represents the 75th percentile (P75) and the bottom limit the 25th percentile (P25). The box bars are related to the 1st (P1) and 99th (P99) percentiles, and the crosses represent the maximum and minimum values, respectively. From Fig. 4, for biases of $1,2,5$ and $10 \%$, mean values of the differences in the effective radius are very small: $0.03,0.34$, 0.41 and $1.01 \%$ for type I (Fig. 3a) and $-0.62,-0.91,-0.49$ and $-0.18 \%$ for type II (Fig. 3b). Values larger than the 25th percentiles (P25) and lower than the $75 \%$ percentiles (P75) are found for the ranges from -1.8 to $1.3 \%$ (type I) and from -0.6 to $4.4 \%$ (type II). Only two outliers are found with relative differences greater than $100 \%$. The latter occur when all the optical channels except $\beta(355 \mathrm{~nm})$ are either overestimated or underestimated. But for these particular cases the baseline deviations are 0.009 or $-0.009 \%$, while the simulated ones are 0.557 and $-0.557 \%$, respectively. These small errors are within the uncertainties associated with the regularization method, and thus these large relative differences are a mathematical artifact created by dividing by small numbers. Tests have also been performed for the other microphysical parameters, and we also found an additive property in the deviations predicted by the results shown in Table 1. Furthermore, very similar additive properties were found for aerosol type III (graph not shown for brevity). Therefore, for the bimodal size distributions used here that cover most of those size distributions obtained by AERONET, we conclude that the results of Table 1 can be reliably used to calculate the deviations in retrieved quantities due to multiple simultaneously biased input data.

We take this result to be an indication that, as mentioned earlier, the solutions found by the inversion technique generally define a local minimum in the multidimensional solution space (e.g., see Fig. 1 in both Veselovskii et al., 2002, 2012). The linear behavior of the deviations in the retrieval due to small changes in the input parameters is a characteristic of displacements from this minimum location. Multiple simultaneous displacements tend also to display this linear behavior. The results here indicate therefore, for biases in the input data of up to approximately $20 \%$, whether for a single channel or multiple ones simultaneously, that the solution space possesses an average linear property and an additive behavior can be assumed. For larger biases in the optical data (e.g., $\pm 30 \%$ ) the additive property is not assured, as under these circumstances different minima in the solution space may be found by the regularization algorithm.

\subsection{Application to the sensitivity of retrievals to the presence of random errors in the optical data}

Up to this point, we have concerned ourselves only with the effects of systematic biases in the input optical data on the retrieved quantities. But in lidar systems, random errors are also present due just to the measurement process itself. Any specific set of $3 \beta+2 \alpha$ data affected by random errors can be considered as a set of biased measurements where the individual biases for each of the data follow a normal distribution. Given the additive property of the systematic errors that we have shown, we can assess the effects of random errors in the optical data by generating random biases in the optical data and computing their deviations in the microphysical parameters from the values given in Table 1 . The sensitivities of the regularization technique to those random errors computed using the procedure just outlined will be compared with previously published ones (e.g., Müller et al., 1999a, b; Veselovskii et al., 2002, 2004).

To assess the sensitivity of the retrievals to random errors, we use the additive properties of the systematic biases just described. The procedure used consists of generating random numbers distributed in a Gaussian way centered at zero with width according to the value of the random error to study. These random errors are applied to each optical channel of the $3 \beta+2 \alpha$ configuration. This procedure was repeated 50000 times for each parameter studied. Also, the initiation of the random number generation is different for each channel in order to avoid the situation where all the random numbers are the same in every channel. Finally, we introduced this random number for every optical datum and computed the corresponding error in the retrieved microphysical parameter using the slopes provided in Table 1. For every set of $3 \beta+2 \alpha$ values, the final error obtained in the microphysical parameter is the sum of the error obtained for each channel. The study of the frequency distributions of the final errors for this large number of simulations yields the effects of random errors. If the frequency distribution is a normal one, the standard deviation (full width at half maximum) provides the final error in the microphysical parameter. Moreover, if the normal distribution is not centered at zero it demonstrates an interesting property: that the presence of systematic errors in the retrieved microphysical property can be induced by random errors in the input optical data. As an illustration, Fig. 5 shows the frequency distribution of the differences in the microphysical parameters studied here, for all aerosol size distributions type I, II and III, where $15 \%$ random error is assumed in all the optical data. Those differences associated with the effects of random errors are in percentages and denoted as "deviation" in the $x$ axis of the histograms.

From Fig. 5 we observe that the frequency distributions possess the expected Gaussian shape for all the microphysical parameters. Most of the frequency distributions are centered essentially at zero, although some significant departures from this value are observed. The percentage changes 

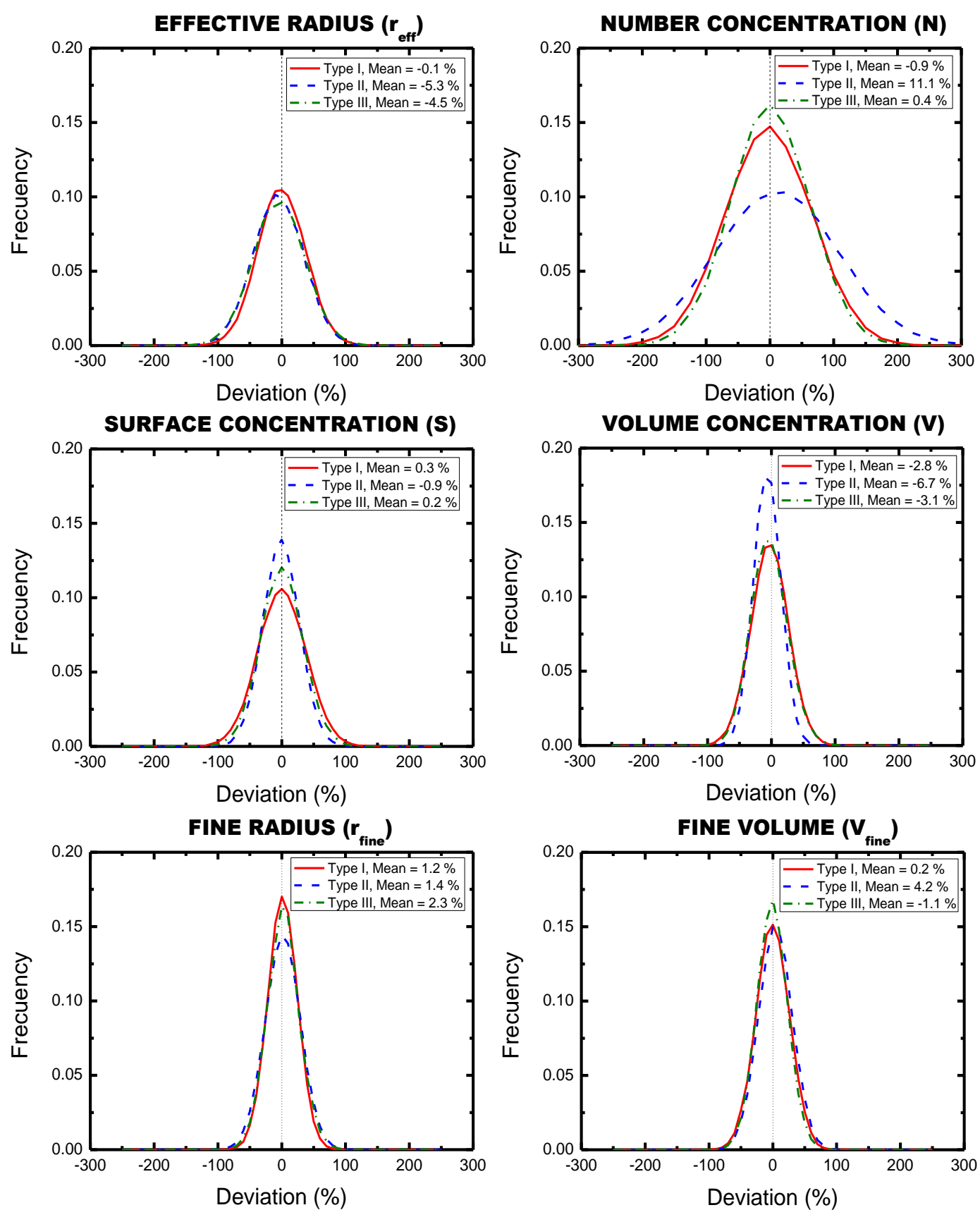

Fig. 5. Frequency distributions of the different microphysical parameters for $15 \%$ random errors in the optical data using 50000 random samplings of the systematic error sensitivities shown in Table 1. The $x$ axis represents the difference between microphysical parameters with no errors in the input optical data and those affected by random errors in the optical data. Random errors were simulated by a normal distribution centered at zero and with a standard deviation of $15 \%$. The random number generator is initialized at different values for each of the 5 optical data used in the $3 \beta+2 \alpha$ lidar configuration. The mean value of the deviation between the microphysical parameter affected by random error and that unaffected by random error is included in the legend.

in the mean values of the distributions are shown in the legend. A shift in the mean value due to the presence of random error is explained by the different linear tendency for positive and negative biases for some input optical data, as discussed earlier to respect Table 1. For example, such departures from zero are observed for retrievals of $r_{\text {eff }}, N$ and $V$ for type II aerosols and are approximately $-5,1$ and $-7 \%$, respectively. On the other hand, the FWHM - or standard deviations - of the normal distributions of Fig. 5 are representative of the sensitivities to $15 \%$ random errors in the optical data. Generally, there are many similarities in the standard deviations between aerosol types I, II and III. We observe 
Table 2. Standard deviations of the frequency distributions of the deviation induced in the microphysical parameters due to random errors in the optical data.

\begin{tabular}{|c|c|c|c|c|c|c|c|c|c|c|c|c|c|c|c|c|c|c|}
\hline \multirow{3}{*}{$\begin{array}{l}\text { Random } \\
\text { Errors (\%) }\end{array}$} & \multicolumn{3}{|c|}{$r_{\text {eff }}$} & \multicolumn{3}{|c|}{$N$} & \multicolumn{3}{|c|}{$S$} & \multicolumn{3}{|c|}{ V } & \multicolumn{3}{|c|}{$r_{\text {fine }}$} & \multicolumn{3}{|c|}{$V_{\text {fine }}$} \\
\hline & Type & Type & Type & Type & Type & Type & Type & Type & Type & Type & Type & Type & Type & Type & Type & Type & Type & Type \\
\hline & I & II & III & I & II & III & I & II & III & I & II & III & I & II & III & I & II & III \\
\hline 5 & 12.5 & 13.1 & 13.7 & 22.5 & 31.8 & 20.5 & 12.5 & 9.5 & 11.2 & 9.8 & 7.2 & 9.5 & 7.7 & 9.2 & 8.4 & 8.7 & 8.8 & 8.1 \\
\hline 10 & 24.9 & 26.2 & 27.2 & 45.0 & 63.6 & 40.8 & 25.1 & 19.1 & 22.3 & 19.6 & 14.4 & 19.0 & 15.5 & 18.4 & 16.8 & 17.4 & 17.6 & 16.1 \\
\hline 15 & 37.2 & 39.2 & 40.8 & 67.6 & 95.2 & 61.4 & 37.7 & 28.5 & 33.4 & 29.5 & 21.5 & 28.5 & 23.3 & 27.6 & 25.3 & 26.1 & 26.3 & 24.1 \\
\hline 20 & 50.0 & 52.6 & 54.8 & 90.1 & 127.3 & 82.1 & 50.2 & 38.2 & 44.6 & 39.3 & 28.8 & 38.0 & 31.1 & 36.9 & 33.8 & 34.9 & 35.2 & 32.2 \\
\hline $10^{*}$ & & $25^{*}$ & & & $70^{*}$ & & & $25^{*}$ & & & $25^{*}$ & & & - & & & - & \\
\hline
\end{tabular}

Table 3. Mean of the differences (in percentages) in the retrieved microphysical parameters due to varying amounts of random error in the optical data.

\begin{tabular}{|c|c|c|c|c|c|c|c|c|c|c|c|c|c|c|c|c|c|c|}
\hline \multirow[b]{2}{*}{$\begin{array}{l}\text { Random } \\
\text { Errors (\%) }\end{array}$} & \multicolumn{3}{|c|}{$r_{\text {eff }}$} & \multicolumn{3}{|c|}{$N$} & \multicolumn{3}{|c|}{$S$} & \multicolumn{3}{|c|}{$V$} & \multicolumn{3}{|c|}{$r_{\text {fine }}$} & \multicolumn{3}{|c|}{$V_{\text {fine }}$} \\
\hline & $\begin{array}{c}\text { Type } \\
\text { I }\end{array}$ & $\begin{array}{c}\text { Type } \\
\text { II }\end{array}$ & $\begin{array}{c}\text { Type } \\
\text { III }\end{array}$ & $\begin{array}{c}\text { Type } \\
\text { I }\end{array}$ & $\begin{array}{c}\text { Type } \\
\text { II }\end{array}$ & $\begin{array}{c}\text { Type } \\
\text { III }\end{array}$ & $\begin{array}{c}\text { Type } \\
\text { I }\end{array}$ & $\begin{array}{l}\text { Type } \\
\text { II }\end{array}$ & $\begin{array}{c}\text { Type } \\
\text { III }\end{array}$ & $\begin{array}{c}\text { Type } \\
\text { I }\end{array}$ & $\begin{array}{c}\text { Type } \\
\text { II }\end{array}$ & $\begin{array}{c}\text { Type } \\
\text { III }\end{array}$ & $\begin{array}{c}\text { Type } \\
\text { I }\end{array}$ & $\begin{array}{l}\text { Type } \\
\text { II }\end{array}$ & $\begin{array}{c}\text { Type } \\
\text { III }\end{array}$ & $\begin{array}{c}\text { Type } \\
\text { I }\end{array}$ & $\begin{array}{c}\text { Type } \\
\text { II }\end{array}$ & $\begin{array}{c}\text { Type } \\
\text { III }\end{array}$ \\
\hline 5 & 0.0 & -1.7 & -1.6 & -0.8 & 3.5 & 0.2 & 0.0 & -0.4 & 0.1 & -1.1 & -2.3 & -1.1 & 0.4 & 0.5 & 0.7 & 0.0 & 1.4 & -0.3 \\
\hline 10 & 0.0 & -3.5 & -3.0 & -1.4 & 7.1 & 0.1 & 0.1 & -0.7 & 0.0 & -1.9 & -4.4 & -2.3 & 0.9 & 1.1 & 1.5 & 0.1 & 2.8 & -0.8 \\
\hline 15 & -0.1 & -5.3 & -4.5 & -1.9 & 11.1 & 0.4 & 0.3 & -0.9 & 0.2 & -2.8 & -6.7 & -3.1 & 1.2 & 1.4 & 2.1 & 0.2 & 4.2 & -1.0 \\
\hline 20 & -0.3 & -7.2 & -5.6 & -2.3 & 15.2 & -0.6 & 0.6 & -1.0 & -0.4 & -3.8 & -9.0 & -4.5 & 1.5 & 1.8 & 3.3 & 0.4 & 5.8 & -1.9 \\
\hline
\end{tabular}

clearly that $V, r_{\text {fine }}$ and $V_{\text {fine }}$ exhibit the smallest sensitivity to the imposed $15 \%$ random errors with a 1-sigma spread in the result of approximately $25 \%$. The effective radius and surface concentration results show moderate sensitivity with 1-sigma values of 30-40\%, while the retrieval of number concentration has the highest sensitivity, with 1-sigma values of $67.6 \%$ for type I, $95.2 \%$ for type II and $61.4 \%$ for type III. As expected, these sensitivities to random error track the results of the sensitivities to systematic errors, where the most sensitive parameter was also found to be number concentration and the least sensitive were volume concentration, fine-mode radius and fine-mode volume concentration.

Using the same procedure as for $15 \%$ random error, Table 2 reports the FWHM - or standard deviations - of normal distributions obtained for other magnitudes of random errors in the optical data ranging from 5 to $20 \%$. We observe, as expected from the linear functions involved, that increasing the random uncertainty increases the deviations found in a linear fashion. Moreover, it is observed again that the largest sensitivities are for $N$, while the lowest are for $V, r_{\text {fine }}$ and $V_{\text {fine. }}$ In the same way, Table 3 reports the means of the deviation of every microphysical property for varying amounts of random uncertainty in the input data. As mentioned above, the departures of these deviations from zero indicate that random uncertainties in the input optical data can induce varying amounts of systematic bias in the retrieved properties. This effect is found more with the type II aerosols that possess a higher fraction of larger particles. Such a population is more likely to have different slopes in Table 1 due to positive and negative biases in the input optical data because of the reduced sensitivity of the MW technique to larger particles. It is this reduced sensitivity to larger particles that, in general, explains the shifting of the mean values in the retrieved distributions due to varying amounts of random error in the input data.

Müller et al. (1999a, b) and Veselovskii et al. (2002, 2004) studied $10 \%$ random uncertainties in the optical data in the $3 \beta+2 \alpha$ lidar configurations by introducing random errors in the optical data and running the regularization code repeatedly. These studies reported that the retrieved uncertainties were on the order of $25 \%$ for $r_{\mathrm{eff}}, V$ and $S, 30 \%$ for $r_{\text {mean }}$ and $70 \%$ for $N$. These values are quite similar to those reported in Table 2 for our computations of $10 \%$ random errors. No evaluations for $r_{\text {fine }}$ and $V_{\text {fine }}$ were done in the studies of Müller et al. (1999a, b) and Veselovskii et al. (2002, 2004). The method shown here for assessing the sensitivity of retrievals to random errors is generally consistent with these earlier results but permits the influence of varying amounts of random error to be studied. It also permits the influence of random errors in different input optical channels to be quantified. We will now apply this capability to the problem of instrument specification.

\section{Application to instrument specification}

The upcoming spaceborne Decadal Survey ACE (AerosolCloud-Ecosystems) mission of NASA (http://dsm.gsfc.nasa. gov/ace/) specifies a high-spectral-resolution lidar as a core instrument to measure vertical profiles of aerosol extinction and backscattering worldwide. These profiles will be used to derive vertically resolved aerosol microphysical properties such as effective radius, number concentration or complex refractive index. The system is anticipated to use the $3 \beta+2 \alpha$ configuration and the regularization technique that has been studied here. The first reports (http://dsm.gsfc.nasa.gov/ace/) call for an accuracy of $\pm 15 \%$ for all backscattering and 
extinction coefficients, and thus the results presented here can be used to infer the anticipated uncertainties in the microphysical properties retrieved using the regularization technique on these $3 \beta+2 \alpha$ spaceborne data when all input data possess $15 \%$ uncertainties. However, the results already presented clearly indicate that, for most quantities, it is uncertainties in the extinction coefficients that need to be constrained more carefully than those in the backscattering data. Volume concentration is an interesting exception to this statement where $\beta(355 \mathrm{~nm})$ for type I aerosols is the optical parameter requiring the smallest uncertainty budget to help reduce the uncertainties in retrievals. In this way, the results obtained here can serve as a guide to hardware designers of multiwavelength lidar instruments in the sense that if tradeoffs need to be made between the performance of one optical channel versus another, the relative sensitivities shown in Table 1 can be used to assess which channels would benefit most from decreased uncertainty in the measurements. Another application of the sensitivities derived here is to algorithm development. Algorithms can introduce systematic uncertainties in the optical data such as through an incorrect assumption of an aerosol-free region, an assumption of the extinction to backscatter ratio or the use of an estimated molecular profile. The results presented here can be used to assess the tolerance for both random and systematic errors in the input optical data due both to instrumentation and to algorithms once uncertainty requirements in the retrieved quantities are established.

\section{Summary and conclusions}

We have presented the results of a study of the sensitivity of the retrievals of aerosol physical parameters using the regularization technique to systematic and random uncertainties in the input optical data. We have focused our study on the set of data consisting of three backscattering coefficients $(\beta)$ at 355,532 and $1064 \mathrm{~nm}$ and two extinction coefficients $(\alpha)$ at 355 and $532 \mathrm{~nm}(3 \beta+2 \alpha$ configuration). These data can be obtained by a lidar system that uses a Nd:YAG laser and combines backscatter with Raman or HSRL channels. Simulations have been done for different bimodal aerosol size distributions that are representative of AERONET climatologies. The values used for aerosol refractive indexes, as well as mode radius and widths, were selected as representative of those climatologies as well. The selected aerosol bimodal size distributions include one with fine-mode predominance (type I), another with predominance of coarse mode but with significant presence of fine mode (type II) and another with predominance of fine mode but with significant presence of coarse mode (type III). Optical data consistent with these bimodal size distributions were generated using Mie theory. Retrievals were performed using these baseline optical data. The optical data were then perturbed by systematic biases in the range $\pm 20 \%$ to study the effects of biases on the retrieved parameters. This threshold value of $\pm 20 \%$ is enough for many practical lidar applications. As the problem of the inversion of microphysical properties is underdetermined, constraints are needed that, in principle, can influence the values retrieved by the algorithm. Particularly, we have found that the range of radius and refractive index used in the inversion did not have a large influence on the sensitivities of the different microphysical particles. However, our results showed that the maximum value of $m_{\mathrm{i}}$ allowed in the retrieval had a significant influence on the value of the refractive index retrieved, supporting earlier results that indicate significant uncertainties in the retrieval of refractive index using the $3 \beta+2 \alpha \mathrm{MW}$ lidar technique studied here.

The microphysical parameters studied included effective radius $\left(r_{\text {eff }}\right)$ and volume $(V)$ as well as number $(N)$ and surface $(S)$ concentration. Also, as the inversion window ranged from 0.075 to $5 \mu \mathrm{m}$, we were able to study the fine mode of the aerosol size distribution $(0.075-0.5 \mu \mathrm{m})$ separately, and thus we have also presented the results for both fine-mode radius $\left(r_{\text {fine }}\right)$ and volume $\left(V_{\text {fine }}\right)$. From these sensitivity tests, the percentage deviations of the microphysical parameters as a function of biases in the optical data presented linear patterns. Generally, these linear patterns presented the same sign of slopes for aerosol type I, II and III and the largest sensitivities were observed for biases in the extinction coefficients $\alpha(355 \mathrm{~nm})$ and $\alpha(532 \mathrm{~nm})$. Moreover, the largest sensitivities were found for $N$, while the least affected parameters were $V, r_{\text {fine }}$ and $V_{\text {fine }}$.

An important result is that we have found an additive property for the deviations induced by the biases in the optical data. This implies that if, for example, several optical data are simultaneously affected by systematic errors, the total deviation in the retrieved quantity can be well approximated by the sum of those deviations computed when each optical input was biased separately. From this additive property, we have been able to compute the effects of random errors in the optical data. Moreover, we have found some systematic differences in the mean retrieved microphysical properties when the retrievals are affected by random errors in the input optical data. The presence of these systematic differences is associated with the different behavior (although with linear patterns) between positive and negative biases in the input optical data, and is due to a reduced sensitivity of the retrieval to the coarse part of the size distribution.

The results presented here cannot be generalized to every possible size distribution as we only focused on bimodal size distributions representative of those obtained by AERONET. Studies of the sensitivities of the microphysical retrieval to errors in the optical data for other size distributions such as one showing trimodal behavior are still needed although the results presented here for three differing bimodal distributions lead one to expect that similar results would be obtained for trimodal distributions as well. The tests performed here showed that the average linearity of the sensitivities in the retrieval to random errors in the input data can be useful for 
a wide range of lidar applications, and thus can be used to establish acceptable error budgets in optical data if maximum permissible errors in the retrieved quantities can be established. Therefore, the values given here for the sensitivities of the microphysical properties to systematic errors in the optical data can be useful for many lidar applications. For example, for the Decadal Survey ACE mission, a multiwavelength lidar is planned. Among their measurement requirements is that the accuracy of the optical data be $\pm 15 \%$. If these uncertainties are taken to be all random, we were able to use the results here to estimate that this implies an uncertainty in the retrieved microphysical properties by the regularization technique of $\sim 40 \%$ for $r_{\text {eff }}, \sim 85 \%$ for $N, \sim 25 \%$ for $S$, $\sim 20 \%$ for $V$, and $16 \%$ for $r_{\text {fine }}$ and $V_{\text {fine }}$, respectively. The results also permit assessing the deviations in the retrievals if the biases in the optical data are systematic and exist in only one or more channels. In this way, trade-off decisions can be made between the retrieval requirements and the hardware configuration of a lidar system taking into account the different sensitivities of the retrievals to biases in the optical data of different channels. We hope these results aid the future design of multiwavelength lidar systems intended for retrieval of aerosol microphysical properties.

Acknowledgements. This work was supported by the NASA/Goddard Space Flight Center, the Spanish Ministry of Science and Technology through projects CGL2010-18782 and CSD2007-00067, the Andalusian Regional Government through projects P10-RNM-6299 and P08-RNM-3568, the EU through ACTRIS project (EU INFRA-2010-1.1.16-262254) and the Postdoctoral Program of the University of Granada. We also express our gratitude to the anonymous referees for their suggestions to improve this work.

Edited by: V. Amiridis

\section{References}

Alados-Arboledas, L., Lyamani, H., and Olmo, F. J.: Aerosol size properties at Armilla, Granada (Spain), Q. J. Roy. Meteorol. Soc., 129, 1395-1413, doi:10.1256/qj.01.207, 2003.

Alados-Arboledas, L., Müller, D., Guerrero-Rascado, J. L., NavasGuzmán, F., Pérez-Ramírez, D., and Olmo, F. J.: Optical and microphysical properties of fresh biomass burning aerosol retrieved by Raman lidar, and star-and sun-photometry, Geophys. Res. Lett., 38, L01807, doi:10.1029/2010g1045999, 2011.

Ansmann, A., Riebesell, M., Wandinger, U., Weitkamp, C., Voss, E., Lahmann, W., and Michaelis, W.: Combined Raman elasticbackscatter LIDAR vertical profiling of moisture, aerosol extinction, backscatter and LIDAR ratio, Appl. Phys. B, 55, 18-28, 1992.

Balis, D., Giannakaki, E., Müller, D., Amiridis, V., Kelektsoglou, K., Rapsomanikis, S., and Bais, A.: Estimation of the microphysical aerosol properties over Thessaloniki, Greece, during the SCOUT-O3 campaign with the synergy of Raman lidar and Sun photometer data, J. Geophys. Res., 115, D08202, doi:10.1029/2009JD013088, 2010.

Böckmann, C., Miranova, I., Müller, D., Scheidenbach, L., and Nessler, R.: Mycrophysical aerosol parameters from multiwavelength lidar, J. Opt. Soc. Am. A, 22, 518-528, 2005.

Bohren, C. F. and Huffman, D. R.: Absorption and scattering of light by small particles, John Wiley \& Sons, Inc., 1998.

Dubovik, O., Holben, B., Eck, T. F., Smirnov, A., Kaufman, Y. J., King, M. D., Tanre, D., and Slutsker, I.: Variability of absorption and optical properties of key aerosol types observed in worldwide locations, J. Atmos. Sci., 59, 590-608, 2002.

Eck, T. F., Holben, B. N., Ward, D. E., Mukelabai, M. M., Dubovik, O., Smirnov, A., Schafer, J. S., Hsu, N. C., Piketh, S. J., Queface, A., Le Roux, J., Swap, R. J., and Slutsker, I.: Variability of biomass burning aerosol optical characteristics in southern Africa during the SAFARI2000 dry season campaign and a comparison of single scattering albedo estimates from radiometric measurements, J. Geophys. Res., 108, 8477, doi:10.1029/2002JD002321, 2003.

Eck, T. F., Holben, B. N., Dubovik, O., Smirnov, A., Goloub, P., Chen, H. B., Chatenet, B., Gomes, L., Zhang, X. Y., Tsay, S. C., Ji, Q., Giles, D., and Slutsker, I.: Columnar aerosol properties at AERONET sites in central eastern Asia and aerosol transport to the tropical mid-Pacific, J. Geophys. Res., 110, D06202, doi:10.1029/2004JD005274, 2005.

Eck, T. F., Holben, B. N., Reid, J. S., Sinyuk, A., Hyer, E. J., O'Neill, N. T., Shaw, G. E., Vande Castle, J. R., Chapin, F. S., Dubovik, O., Smirnov, A., Vermote, E., Schafer, J. S., Giles, D., Slutsker, I., Sorokine, M., and Newcomb, W. W.: Optical properties of boreal region biomass burning aerosols in central Alaska and seasonal variation of aerosol optical depth at an Arctic coastal site, J. Geophys. Res., 114, D11201, doi:10.1029/2008JD010870, 2009.

Eck, T. F., Holben, B. N., Sinyuk, A., Pinker, R. T., Goloub, P., Chen, H., Chatenet, B., Li, Zi., Singh, R. P., Tripathi, S. N., Reid, J. S., Giles, D. M., Dubovik, O., O’Neill, N. T., Smirnov, A., Wang, P., and Xia, X.: Climatological aspects of the optical properties of fine/coarse mode aerosol mixtures, J. Geophys. Res., 115, D19205, doi:10.1029/2010JD014002, 2010.

Forster, P., Ramaswamy, V., Artaxo, P., Berntsen, T., Betts, R., Fahey, D. W., Haywood, J., Lean, J., Lowe, D. C., Myhre, G., Nganga, J., Prinn, R., Raga, G., Schulz, M., and Dorland, R. V.: Changes in Atmospheric Constituents and in Radiative Forcing, Climate Change 2007: The Physical Science Basis, In: Contribution of Working Group I to the Fourth Assessment Report of the Intergovernmental Panel on Climate Change, edited by: Solomon, S., Qin, D., Manning, M., Chen, Z., Marquis, M., Averyt, K. B., Tignor, M., and Miller, H. L., 2007.

Grund, C. J. and Eloranta, E. W.: University-of-Wisconsin High Spectral Resolution Lidar, Opt. Eng., 30, 6-12, 1991.

Haywood, J. M. and Boucher, O.: Estimates of the direct and indirect radiative forcing due to tropospheric aerosols: A review, Rev. Geophys., 38, 513-543, 2000.

Heintzenberg, J., Muller, H., Quenzel, H., and Thomalla, E.: Information content of optical data with respect to aerosol properties: numerical studies with a randomized minimization-searchtechnique inversion algorithm, Appl. Optics, 20, 1308-1315, 1981. 
Holben, B. N., Eck, T. F., Slutsker, I., Tanré, D., Buis, J. P., Setzer, A., Vermote, E., Reagan, J. A., Kaufman, Y. J., Nakajima, T., Lavenu, F., Jankowiak, I., and Smirnov, A.: AERONET - A Federated instrument network and data archive for aerosol characterization, Remote Sens. Environ., 66, 1-16, 1998.

Horvath, H., Gunter, R. L., and Wilkison, S. W.: Determintation of the coarse mode of the atmospheric aerosol using data from a forward-scattering spectrometer probe, Aerosol Sci. Technol., 12, 964-980, 1990.

Kaufman, Y. J., Wald, A. E., Remer, L. A., Gao, B. C., Li, R. R., and Flynn, L.: The MODIS 2.1- $\mu \mathrm{m}$ channel - Correlation with visible reflectance for use in remote sensing of aerosol, IEEE T. Geosci. Remote, 35, 1286-1298, 1997.

Liou, K. N.: An introduction to atmospheric radiation, International Geophysics Series, Vol. 84, edited by: Dmowska, R., Holtan, J. T., and Rossby, H. T., 2002.

Kokhanovsky, A. A.: Light scattering media optics, Problems and solutions, Springer-Verlag, 2004.

Mischenko, M. I., Hovenir, J. W., and Travis, L.: Light scattering by nonspherical particles. San Diego, Academic Press, 690 pp., 2000.

Müller, D., Wandinger, U., and Ansmann, A.: Mycrophysical particle parameters from extinction and backscatter lidar data by inversion with regularization: theory, Appl. Optics, 38, 2346-2357, 1999a.

Müller, D., Wandinger, U., and Ansmann, A.: Mycrophysical particle parameters from extinction and backscatter lidar data by inversion with regularization: simulation, Appl. Optics, 38, 23582368, 1999b.

Müller, D., Wagner, F., Wandinger, U., Ansmann, A., Wendisch, M., Althausen, D., and von Hoyningen-Huene, W.: Mycrophysical particle parameters from extinction and backscatter lidar data by inversion with regularization: experiment, Appl. Optics, 39, 1879-1892, 2000.

Müller, D., Wandinger, U., Althausen, D., and Fiebig, M.: Comprehensive particle characterizations from three-wavelength Ramanlidar observations: case study, Appl. Optics, 40, 4863-4869, 2001.

Müller, D., Mattis, I., Ansmann, A., Wehner, B., Althausen, D., Wandinger, U., and Dubovik, O.: Closure study on optical and microphysical properties of a mixed urban and Arctic haze air mass observed with Raman lidar and Sun photometer, J. Geophys. Res., 109, D13206, doi:10.1029/2003JD004200, 2004.

Müller, D., Mattis, I., Wandinger, U., Ansmann, A., Althausen, D., and Stohl, A.: Raman lidar observations of aged Siberian and Canadian forest fire smoke in the free troposphere over Germany in 2003: Microphysical particle characterization, J. Geophys. Res., 110, D17201, doi:10.1029/2004JD005756, 2005.

Müller, D., Kolgotin, A., Mattis, I., Petzold, A., and Stohl, A.: Vertical profiles of microphysical particle properties derived from inversion with two-dimensional regularization of multiwavelength Raman lidar data: experiment, Appl. Optics, 50, 2069-2079, 2011.

Navas-Guzmán, F., Müller, D., Bravo-Aranda, J. A., GuerreroRascado, J. L., Granados-Muñoz, M. J., Pérez-Ramírez, D., Olmo, F. J., and Alados-Arboledas, L.: Eruption of the Eyjafjallajokull volcano in spring 2010: Multiwalength Raman lidar measurements of sulphate particles in the lower troposphere, J. Geophys. Res., 118, 1-10, doi:10.1002/jgrd.50116, 2013.
Noh, Y. M., Müller, D., Shin, D. H., Lee, H., Jung, J. S., Lee, K. H., Cribb, M., Li, Z., and Kim, Y. J.: Optical and microphysical properties of severe haze and smoke aerosol measured by integrated remote sensing techniques in Gwangju, Korea, Atmos. Environ., 43, 879-888, 2009.

O’Neill, N. T., Thulasiraman, S., Eck, T. F., and Reid, J. S.: Robust optical features of fine mode size distributions: Application to the Quebec smoke event of 2002, J. Geophys. Res., 110, D11207, doi:10.1029/2004JD005157, 2005.

Ogunjobi, K.O., He, Z., and Simmer, C.: Spectral aerosol optical properties from AERONET sun-photometric measurements over West Africa, Atmos. Res., 88, 89-107, 2008.

Papayannis, A., Mamouri, R. E., Amiridis, V., Remoundaki, E., Tsaknakis, G., Kokkalis, P., Veselovskii, I., Kolgotin, A., Nenes, A., and Fountoukis, C.: Optical-microphysical properties of Saharan dust aerosols and composition relationship using a multi-wavelength Raman lidar, in situ sensors and modelling: a case study analysis, Atmos. Chem. Phys., 12, 4011-4032, doi:10.5194/acp-12-4011-2012, 2012.

Pérez-Ramírez, D., Lyamani, H., Olmo, F. J., Whiteman, D. N., and Alados-Arboledas, L.: Columnar aerosol properties from sunand-star photometry: statistical comparisons and day-to-night dynamic, Atmos. Chem. Phys., 12, 9719-9738, doi:10.5194/acp12-9719-2012, 2012.

Qing, P., Nakane, H., Sasano, Y., and Kitamura, S.: Numerical simulation of the retrieval of aerosol size distribution from multiwavelength laser radar measurements, Appl. Optics, 28, 5259-5265, 1989.

Schafer, J. S., Eck, T. F., Holben, B. N., Artaxo, P., and Duarte, A. F.: Characterization of the optical properties of atmospheric aerosols in the Amazonia from long-term AERONET monitoring (1993-1995 and 1999-2006), J. Geophys. Res., 113, D04204, doi:10.1029/2007JD009319, 2008.

Seinfield, J. H. and Pandis, S. N.: Atmospheric Chemistry and Physics from air pollution to climate change, John Wiley \& Sons, 1998.

She, C. Y.: Spectral Structure of Lasaer Light Scattering Revisited: Bandwidths of Nonresonant Scattering Lidars, Appl. Optics, 40, 4875-4884, 2001.

She, C. Y., Alvarez, R. J., Caldwell, L. M., and Krueger, D. A.: High-Spectral-Resolution Rayleigh-Mie Lidar Measurements of Vertical Aerosol and Atmospheric Profiles, Appl. Phys. B, 55, 154-158, 1992.

Shipley, S. T., Tracy, D. H., Eloranta, E. W., Trauger, J. T., Sroga, J. T., Roesler, F. L., and Weinman, J. A.: High Spectral Resolution Lidar to Measure Optical-Scattering Properties of Atmospheric Aerosols, 1. Theory and Instrumentation, Appl. Optics, 22, 3716-3724, 1983.

Smirnov, A., Holben, B. N., Kaufman, Y. J., Dubovik, O., Eck, T. F., Slutsker, I., Pietras, C., and Halthore, R. N.: Optical properties of atmospheric aerosol in maritime environments, J. Atmos. Sci., 59, 501-523, 2002.

Smirnov, A., Holben, B. N., Dubovik, O., Frouin, R., Eck, T. F., and Slutsker, I.: Maritime component in aerosol optical models derived from Aerosol Robotic Network data, J. Geophys. Res., 108, 4033, doi:10.1029/2002JD002701, 2003. 
Tesche, M., Müller, D., Gross, S., Ansmann, A., Althausen, D., Freudenthaler, V., Weinzierl, B., Veira, A., and Petzold, A.: Optical and microphysical properties of smoke over Cape Verde inferred from multiwavelength lidar measurements, Tellus B, 63, 677-694, 2011.

Veselovskii, I., Kolgotin, A., Griaznov, V., Müller, D., Wandinger, U., and Whiteman, D.: Inversion with regularization for the retrieval of tropospheric aerosol parameters from multi-wavelength lidar sounding, Appl. Optics, 41, 3685-3699, 2002.

Veselovskii, I., Kolgotin, A., Griaznov, V., Müller, D., Franke, K., and Whiteman, D. N.: Inversion of multi-wavelength Raman lidar data for retrieval of bimodal aerosol size distribution, Appl. Optics, 43, 1180-1195, 2004.

Veselovskii, I., Kolgotin, A., Müller, D., and Whiteman, D. N.: Information content of multiwavelength lidar data with respect to microphysical particle properties derived from eigenvalue analysis, Appl Optics, 44, 5292-5303, 2005.

Veselovskii, I., Whiteman, D. N., Kolgotin, A., Andrews, E., and Korenskii, M.: Demonstration of aerosol property profiling by multi-wavelength lidar under varying relative humidity conditions, J. Atmos. Ocean. Tech., 26, 1543-1557, 2009.

Veselovskii, I., Dubovik, O., Kolgotin, A., Lapyonok, T., Di Girolamo, P., Summa, D., Whiteman, D. N., Mishchenko, M., and Tanré, D.: Application of randomly oriented spheroids for retrieval of dust particle parameters from multiwavelength lidar measurements, J. Geophys. Res., 115, D21203, doi:10.1029/2010JD014139, 2010.

Veselovskii, I., Dubovik, O., Kolgotin, A., Korenskiy, M., Whiteman, D. N., Allakhverdiev, K., and Huseyinoglu, F.: Linear estimation of particle bulk parameters from multi-wavelength lidar measurements, Atmos. Meas. Tech., 5, 1135-1145, doi:10.5194/amt-5-1135-2012, 2012.
Veselovskii, I., Whiteman, D. N., Korenskiy, M., Kolgotin, A., Dubovik, O., Perez-Ramirez, D., and Suvorina, A.: Retrieval of spatio-temporal distributions of particle parameters from multiwavelength lidar measurements using the linear estimation technique and comparison with AERONET, Atmos. Meas. Tech., 6, 2671-2682, doi:10.5194/amt-6-2671-2013, 2013.

Wagner, J., Ansmann, A., Wandinger, U., Seifert, P., Schwarz, A., Tesche, M., Chaikovsky, A., and Dubovik, O.: Evaluation of the Lidar/Radiometer Inversion Code (LIRIC) to determine microphysical properties of volcanic and desert dust, Atmos. Meas. Tech., 6, 1707-1724, doi:10.5194/amt-6-1707-2013, 2013.

Wandinger, U., Müller, D., Böckmann, C., Althausen, D., Matthias, V., Bösengerb, J., Weib, V., Fiebig, M., Wendisch, M., Stohl, A., and Ansmann, A.: Optical and microphysical characterization of biomass burning and industrial-pollution aerosols from multiwavelength lidar and aircraft measurements, J. Geophys. Res., D218115, doi:10.1029/2000JD000202, 2002.

Whiteman, D. N., Melfi, S. H., and Ferrare, R. A.: Raman lidar system for the measurement of water vapor and aerosols in the Earth's atmosphere, Appl. Optics, 31, 3068-3082, 1992.

Xia, X., Li, Z., Holben, B., Wang, P., Eck, T., Chen, H., Cribb, M., and Zhao, Y.: Aerosol optical properties and radiative effects in the Yangtze Delta region of China, J. Geophys. Res., 114, D22S12, doi:10.1029/2007JD008859, 2007.

Yang, X. and Wenig, M.: Study of columnar aerosol size distribution in Hong Kong, Atmos. Chem. Phys., 9, 6175-6189, doi:10.5194/acp-9-6175-2009, 2009. 